\title{
Experimental Analysis of the Supply Pressure Variation of the Hydraulic System
}

\author{
http://dx.doi.org/10.3991/ijes.v2i4.4118 \\ R.M. Castro ${ }^{1}$, Y.M. Morona ${ }^{1}$, K. Machado ${ }^{1}$, L. C. C. Cavaler ${ }^{1}$, A. S. Rocha ${ }^{2}$ \\ ${ }^{1}$ Faculty SATC, Criciúma, SC - Brazil, \\ ${ }^{2}$ Federal University of Rio Grande do Sul - UFRGS, Porto Alegre, RS - Brazil
}

\begin{abstract}
This study aimed to analyze the characteristics of the variation in supply pressure in a hydraulic system under different conditions of operation. First constructive and operating characteristics of the major components analyzed were presented, these being the proportional directional valve, pressure relief valve direct operated (relief valve) and the accumulator. Subsequently, addressed the relationship between the operation of the relief valve and the behavior of the supply pressure. In the experiments, the proportional directional valve is subjected to different conditions of pressure difference and aperture alternating also, the use of an accumulator in the circuit. The results show the relation between the operating conditions of the hydraulic circuit and the change in supply pressure.
\end{abstract}

Index Terms-Directional proportional, Relief valve, Pressure supply.

\section{INTRODUCTION}

Can be defined as a hydraulic set of physical elements associated to conveniently using a fluid to transfer energy allows the transmission and control of forces and movements. Currently, in terms of technology development efforts, hydraulic systems find application in almost all fields of activity, from mining to industrial space. Because of this, highlights that the recent growing interest and need for more industrial adequate to meet the market demands hydraulic systems are factors that favor the funding of academic research dedicated to increasing knowledge hydraulics [1].

Most hydraulic systems are equipped with a pressure relief valve (relief valve) that keeps the working pressure of the system (supply pressure) to a predetermined level. This component protects both the hydraulic pump and the electric motor of an excessive increase in system pressure through the partial or total diverting flow provided by the pump [2].

However, due to the static response of the relief valve, supply pressure fluctuations arising from the amendment present the flow passing through it. This change in the working condition of the relief valve is caused, for example, after pressing the directional control valve. Depending on the application this behavior should be avoided [3].
The variation in supply pressure degrades the performance of the hydraulic actuator trajectory tracking. In this case, due to the absence of an accumulator, it is necessary to work at low speeds so that the variations in flow and therefore the pressure will be slower and the pressure control valves able to maintain the supply pressure constant as possible. The drop in supply pressure directly influences the hydraulic subsystem, damaging the follow-up required hydraulic force, which consequently affects the mechanical subsystem, increasing the trajectory tracking errors [4].

This work analyzes the characteristics of fluctuations in supply pressure, checking the relationship between the operating conditions of the hydraulic system, ie opening of the proportional directional valve and loading the cylinder, and the behavior of the relief valve in a hydraulic system, in addition to analyze the influence of the energy accumulator in the behavior of this phenomenon.

\section{LITERATURE REVIEW}

A hydraulic circuit can be divided into two parts: the circuit of action that encompasses the parts that promote action on the load, and the unit responsible power circuit for supplying hydraulic power for the circuits of activity. The components of a circuit may vary according to the needs of the project in order to adjust them several applications [5].

The valves control and direct the fluid from the pump outlet when returning to the reservoir. The relief valve is almost always the first valve located after the fluid leaves the pump. In a simple circuit probably the second valve used is a directional control valve [6]. The type of pressure control valve is used more relief valve (VA), since that is found on virtually all hydraulic systems. It is a normally closed valve, whose function is to limit the pressure there is a maximum value specified by the partial or total bypass flow from the pump to the reservoir. There are many types of this kind of relief valve, but the concepts discussed in this paper about the VA refer to the pressure relief valve direct operated, Figure 1(a), [7].

The relief valve is basically composed of a shutter which is held in its seat by the effect of the spring force 
pre-set by a screw. The supply pressure, $P_{s}$ acting on the area of the shutter produces a force (pressing force) that directly opposes the preload force of the compression spring, so that the minimum opening pressure of the valve, $P$ is determined the ratio between the strength of pre-compression, $F_{m}$ and $A_{p}$ area subject to the action of supply pressure, $A_{p}[1]$. The minimum opening pressure $F_{m}$ and strength of pre-spring compression adjustment Fm are given as follows [8], Equation (1) and (2):

$$
\begin{gathered}
P_{r}=\frac{F_{m}}{A_{p}} \\
F_{m}=k \cdot x_{0}
\end{gathered}
$$

Where:

$A_{p}=$ Area Shutter subject to the action of pressure $P_{s}$ $k=$ Elastic spring constant

$x_{0}=$ Course precompression spring

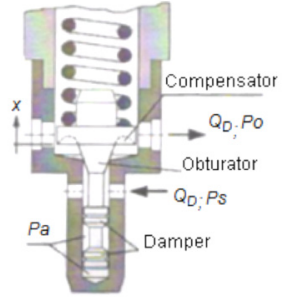

(a)

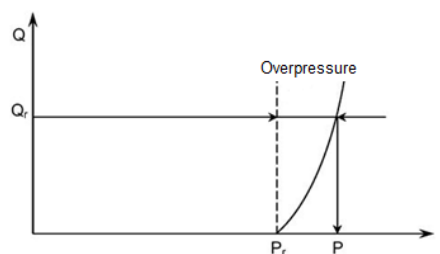

(b)
Figure 1. Principle of operation of the pressure relief valve, direct operated. (a) the constructive-way [1] e (b) static feature [10]

Any pressure increase above the minimum opening pressure $P_{r}$ causes the shutter to move allowing the adjustment of pressure by diverting flow from the pump to the reservoir. The pressure difference $\left(P_{s}-P_{r}\right)$ sets the aperture and shutter flow is described following the Bernoulli Equation 3 [9]. The flow through the VA is given by [10]:

$$
Q_{D}=C_{d} \cdot \omega \frac{A_{p}}{k}\left(P_{s}-P_{r}\right) \sqrt{\frac{2 P_{s}}{\rho}}
$$

Where:

$Q_{D}=$ Flow diverted through the VA

$P_{S}=$ Supply pressure

$P_{r}=$ Minimum opening pressure of VA

$A_{p}=$ Area the shutter subject to supply pressure

$k=$ Spring stiffness

$C_{d}=$ Discharge coefficient

$\omega=$ Proportionality coefficient of orifice area control

$\rho=$ Specific mass of the fluid

According to the behavior described in Figure 1 (b), states that after the opening of the VA, the spring force varies with displacement of the shutter, $\mathrm{x}$. The pressure difference $\left(P-P_{r}\right)$ is called pressure, and the greater the displacement of the shutter against the spring (and the greater stiffness of the spring), the larger the effect of the pressure produced by the additional spring force. Thus, it can be stated that the higher the diverted flow overpressure. This shows that the maximum pressure $P$, corresponds to the total flow diverted by the VA, $Q_{r}$. When $P=P_{r}$, pressure and preload force compression spring are in balance, and with it, the VA remains closed. On business papers the static characteristics of the VA are provided assuming that the flow through this is the independent variable. In Figure 2 where a typical curve of a pressure relief valve provided by manufacturers of this type of valve is shown, it is observed that by modifying the working condition of 1 to 2 due to the change in flow, pressure is affected [10].

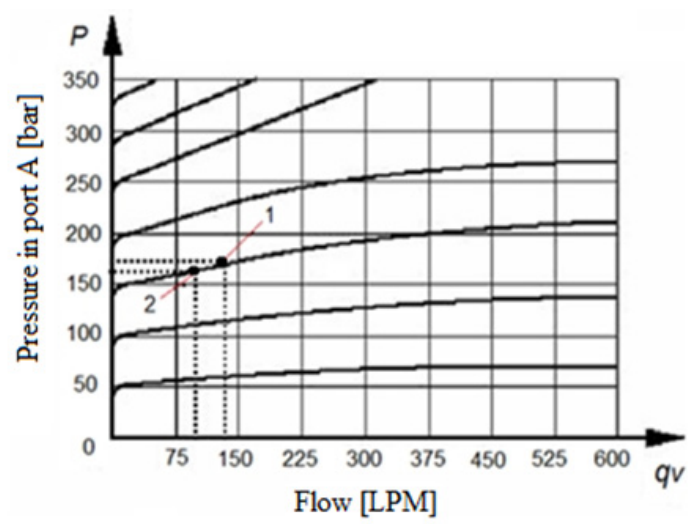

Figure 2. Typical curve of steady state of a relief valve [4]

\section{EXPERIMENTAL PROCEDURE}

The hydraulic circuit used in the experiments was assembled in order to simulate the performance of a hydraulic system subjected to an external load. The circuit performance is composed of the following components: Symmetrical through-rod double action, RAGI manufacturer, model RHI01SLBRTBD200AEXX, the piston diameter of $25 \mathrm{~mm}$, rod diameter $18 \mathrm{~mm}, 200 \mathrm{~mm}$ stroke cylinder; Symmetrical proportional directional valve, direct operated, with pressure balance, without electrical position feedback 4/3, Vickers manufacturer, maximum flow of 1.5 LPM, maximum operating pressure of $120 \mathrm{bar}$, input signal \pm $10 \mathrm{~V}$;

A unit of power used to generate hydropower has the following components: Gear pump with capacity of 3.5 GPM maximum flow rate, operating pressure of 0-60 bar, maximum pressure of 100 bar; Electric motor drive with power of $0.5 \mathrm{HP}$; Bourdon type pressure gauge to check the pressure setting; Pressure relief valve direct operated; Energy storage diaphragm, FCH manufacturer, model 108498-01125, gas volume of $0.75 \mathrm{~L}$ and a maximum pressure of 210 bar. 


\section{A. Charging System and Data Acquisition System}

For loading of the hydraulic cylinder used a system with steel blocks with a mass of about $20 \mathrm{~kg}$ each hydraulic cylinder attached to a cable, moving vertically through a pulley. Through this system the cylinder was fired with three loading conditions, 20,40 and $60 \mathrm{~kg}$, thus generating three different values of load pressure $P_{c}$ and knowing that the pressure difference in pressure differential VDP is obtained from the subtraction between the pressure $P_{s}$ supply and pressure load $P_{c}$, modifying the loading caused three conditions of pressure difference pressure differential on the VDP. The pressure in the supply line was measured by a pressure transmitter, GEFRAN manufacturer, model TKN1EB01CMV, measuring range $0-100$ bar, and uncertainty \pm 0.5 bar, input signal $0-10 \mathrm{~V}$.

The signals measured by the transmitter were sent to a device data acquisition, USB 6008 board. Using LabView (Laboratory Virtual Instrument Engineering Workbench) software, software was developed that allowed the visualization of the signal measured by the pressure transmitter and the generation of graphics necessary to interpret the data acquired by USB 6008 board. The sampling period of the data acquisition system was $0.001 \mathrm{~s}$.

\section{B. Experiments on Bench Study}

The experiments performed in the hydraulic circuit based on the displacement of the cylinder by pushing VDP, alternating operating conditions of the circuit performance in each test. For each test run is triggered VDP with different values of control signal (valve opening) and the loading hydraulic cylinder. Values of the step-like command set on the electronic chart to drive the voltage VDP were $4,6,8$ and $10 \mathrm{~V}$ (ie, command signals openings or equal to $40,60,80,100 \%$ ) and loading conditions of the cylinder 20,40 and $60 \mathrm{~kg}$. All tests performed with the conditions described were made with and without the presence of the accumulator in the hydraulic circuit, this control being done through a record of opening and closing of the accumulator system found in the same block safety (Figure 3 ).

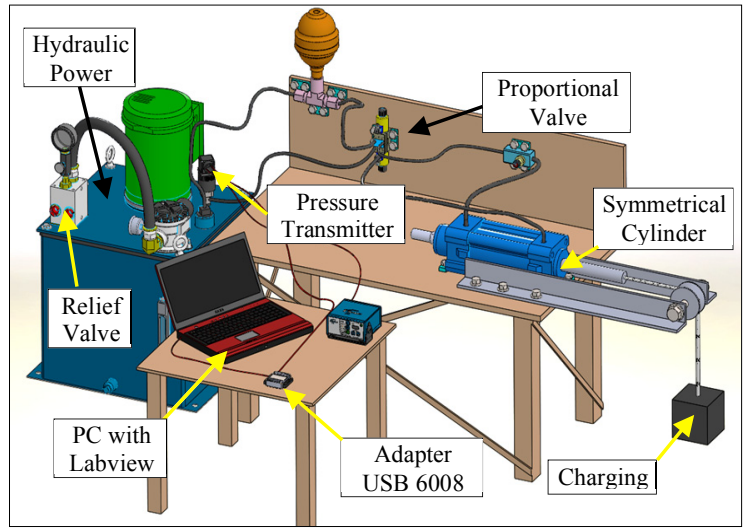

Figure 3. Components of the bench study
According to Figure 4, the flow delivered by the pump $\left(Q_{b}\right)$ equals the sum of the flow diverted by the VA $\left(Q_{d}\right)$ and available flow in the hydraulic circuit $\left(Q_{c}\right)$. Therefore, disregarding the compressibility of the fluid, the change in flow $Q_{c}$ controlled by VDP causes the change in flow diverted by the VA.

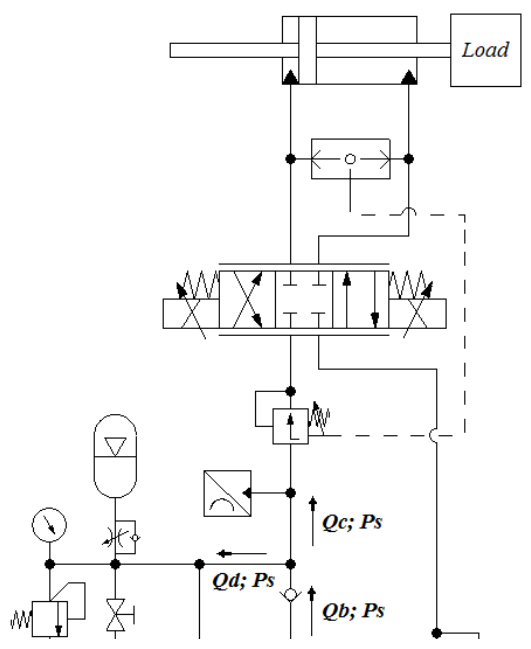

Figure 4. Hydraulic diagram used in the experiment

The minimum opening VDP $40 \%$ (command) was determined assuming the internal leakage this happens to be greater for less than this amount opening. The internal leakage in this case could, in the case of this work, compromising the results of the variation of $P_{S}$ because during the performance of a portion of VPD $Q_{c}$ would go directly to the reservoir rather than being diverted by the VA.

The flow rate passing through the VDP used in the experiments has a similar graph to that described in Figure 5 behavior. According to the chart the flow through the VDP is dependent on both the opening signal as the difference in pressure acting on the same, this relation is observed through the characteristic curves for each operating condition. Thus, it was considered that the flow through the VPD was different for each test.

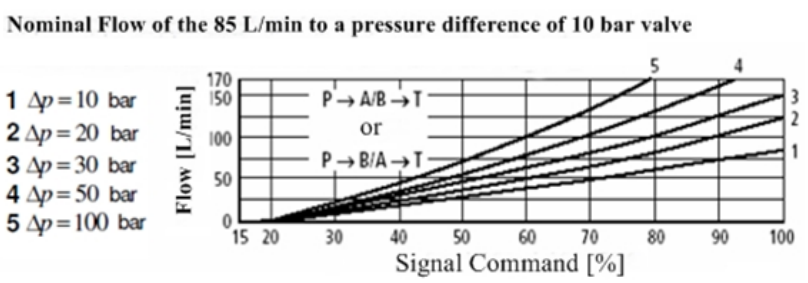

Figure 5. Graph command signal versus of a flow proportional valve [4].

The supply pressure was initially set at 55 bar \pm 1 bar $\left(P_{A}\right)$ because this value is enough to overcome the loading cylinder, where it has been measured by the pressure 
transmitter for the return of the cylinder, ie in the direction opposite the weight force of the blocks. The cylinder moved in each test approximately $180 \mathrm{~mm}$, avoiding that way, that it reached the end of its stroke and impairs the measurement of supply pressure.

The following are some considerations made regarding the parameters adopted for the experiments: the line pressure of the reservoir was considered zero, pressure loss in piping and circuit components have been disregarded, dynamic Drive VDP was disregarded and force of this friction in the loading system was disregarded.

\section{RESULTS AND ANALYSIS}

According to the relationship between $Q_{C}, Q_{B}, Q_{D}$ (Figure 4) the opening of the VDP caused the change of flow diverted by the VA, the VA pushing the shutter to move between intermediate positions between its maximum aperture and its closure as the conditions of each test.

The results obtained have demonstrated both the dynamic behavior such as pressure drop $P_{S}$ based on changes in the working conditions of the control valves used in hydraulic circuit. In the analysis of the results also compared the influence of the action of the accumulator in this phenomenon when this component was used in the circuit.

\section{A. Analysis of the Dynamic Behavior of Supply Pressure}

For analysis of the dynamic behavior of $P_{S}$ used the results obtained with and without using the accumulator in circuit with a load of $20 \mathrm{~kg}$ in the cylinder and openings VDP 40 and 100\%. The results were compared in order to be able to examine the relationship between the operation of the circuit components in the behavior of $P_{S}$.

\section{- Results without the use of accumulator in the circuit}

The Figure 6 and 7 show the behavior of the roller $P_{S}$ loaded with a mass of $20 \mathrm{~kg}$, and the opening of the VDP $100 \%$ and $40 \%$, respectively, without the presence of the accumulator in the circuit.

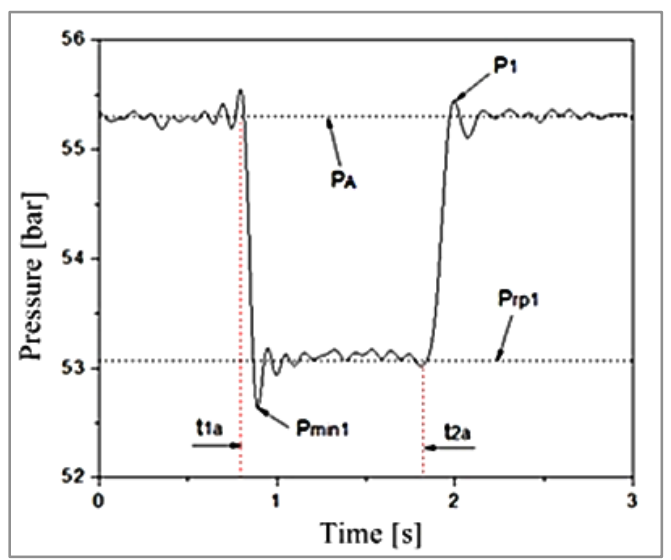

Figure 6. Dynamic behavior of supply pressure without the use of the accumulator with opening of $100 \%$ in the VDP.

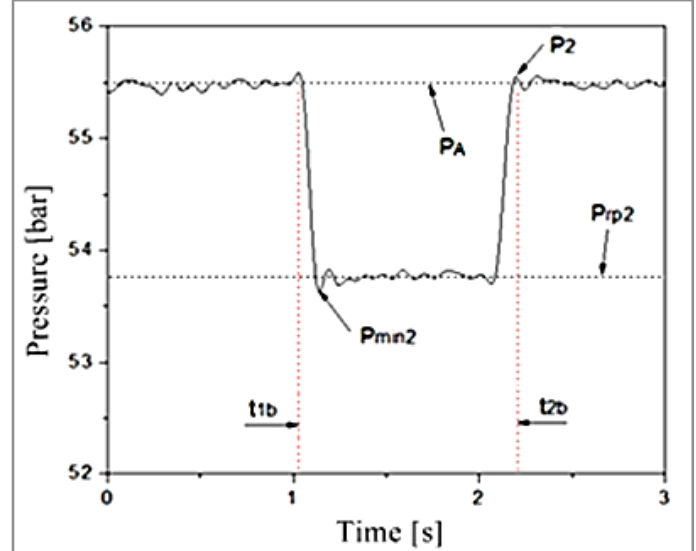

Figure 7. Dynamic behavior of supply pressure without the use of the accumulator with opening of $40 \%$ in the VDP.

Initially, before the opening of the VDP $P_{S}$ pressure is permanently at the value set at the $\mathrm{VA}, P_{A}$, displaying only pulsations arising from the operation of the hydraulic pump. After the activation of the VDP moments $t_{1 a}$ and $t_{1 b}$, part of the pump $Q_{B}$ was directed to the circuit by the VDP, the diminishing with this $Q_{D}$ flow diverted by the VA. As noted in both cases, Figures 6 and 7 , after the change in working conditions in the control valves observed pressure drop in supply, where it hovered until it reaches the steady state value and $P_{r p 1}$ and $P_{r p 2}$. The oscillation $P_{S}$ occurred due to the operation of the mechanical device of VA.

The mechanical device that controls the flow through the VA composed of the shutter, the spring and damper tuning, has modeled as a damped spring-mass system behavior [11]. After reduction of the flow VA shutter moves in the direction to decrease the valve opening and due to the delay in the mechanical response of this device, the shutter continued to move causing minimum peaks occur $P_{S}$, and $P_{\min 1} P_{\min 2}$, Figure 6 and 7 , respectively. The effect of damping of this oscillation arises in reaction to movement of the shutter, the restriction to flow through the radial clearance existing between the piston (damper) and the jacket of the damping system [1].

It is observed that in the first case, Figure 6, with the valve fully open (opening $=100 \%$ ) directed into the flow circuit is greater than in the second case 7 (opening $=$ $40 \%$ ); causing a further decrease in the flow diverted through the VA. These oscillations in the displacement of the shutter and system pressure, $P_{S}$, result from the disruption of flow and pressure, caused by the sudden increase of pressure in the hydraulic system. Leaving it is concluded that the amplitude of oscillation $P_{\min 1} P_{S}$ was higher in the case described in Figure $7 \mathrm{a}$ for having generated a disturbance of higher flow in the flow control device VA [1].

The closing moments of the VDP $t_{2 a}$ e $t_{2 b}$, caused flow in the circuit passed again being diverted by the VA. Due to the operation of the VA, the rapid increase in flow through this caused the sudden increase in supply pressure, where again it can be seen in both cases the 
effect of the delay in the response of the device of VA, causing pressure spikes $P_{1} \mathrm{e} P_{2}$, as Figure 6 and 7, respectively. After this fact was damped oscillation until the value of the steady pressure initially $P_{A}$ adjusted.

It was noted that in both cases the values $P_{1}$ and $P_{2}$ were very close and relatively low. However, it is known that in cases where the flow and pressure are higher than the values used in the experiments these pressure peaks, as seen in Figure 6 and 7 can decrease the pump life.

\section{- Results using the accumulator in the circuit}

Initially the supply pressure $P_{S}$ is permanently at $P_{A}$ value set in VA, with pulsations again due to the pump. However, as Figure 8 and 9, the use of the accumulator circuit has caused a change in the dynamic behavior of the supply pressure during the opening of the VDP in relation to the results without the use of the accumulator.

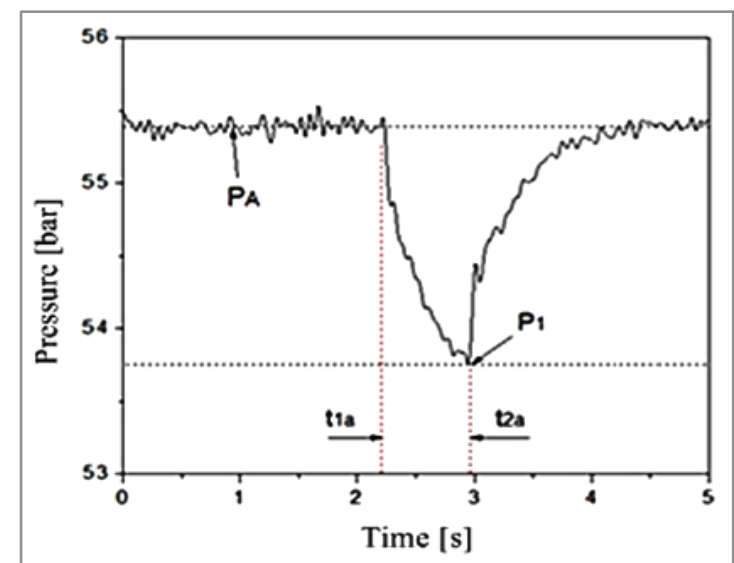

Figure 8. Dynamic behavior of supply pressure using the accumulator with opening of $100 \%$ in the VDP.

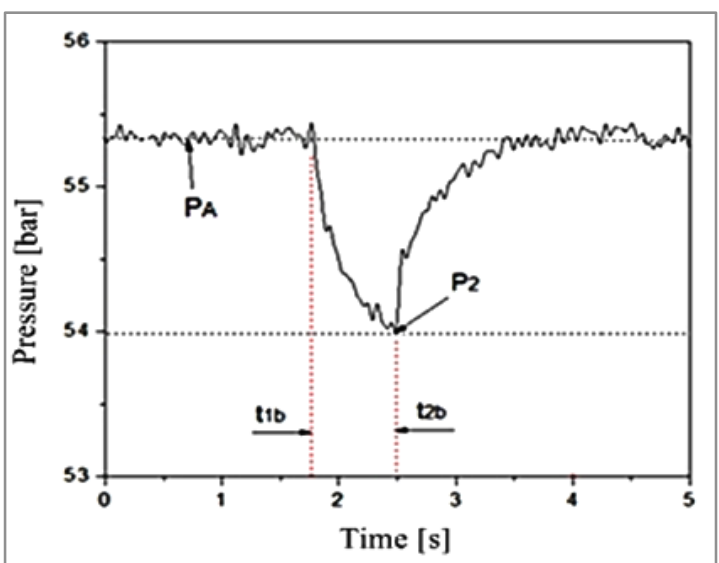

Figure 9. Dynamic behavior of supply pressure using the accumulator with opening of $40 \%$ in the VDP.

In the cases analyzed the supply pressure $P_{S}$ did not show the behavior in steady state during the opening of the VDP may be noted that the fall of $\mathrm{P}_{-} \mathrm{S}$ soon after the opening of the valve occurred gradually until the closing moments of the VDP.
Analyzing the two cases, it was found that after initially opening the VDP in moments $t_{1 a}$ and $t_{1 b}$, part of the flow delivered by the pump $Q_{C}$ was directed to the circuit causing the drop in supply pressure due to operation of VA. From this moment the pressure inside the accumulator became higher than the value of $P_{S}$, allowing the discharge of the pressurized fluid within the accumulator circuit. As part of flow $Q_{C}$ was provided by the accumulator drive, analyzing the $Q_{C}, Q_{B}, Q_{D}$, it is concluded that there was less variation in the flow diverted by the VA and, consequently, smaller drops $P_{S}$ $\left(P_{1}\right.$ and $\left.P_{2}\right)$.

Analyzing the behavior of $P_{S}$, it was noted that his fall was more marked after opening the VDP due to dynamic operation of the accumulator. From the onset of action the accumulator in the circuit, the rate of change of $P_{S}$ decreased characterizing the damping effect generated by the accumulator. In this way, use of the accumulator prevented sudden drop in $P_{S}$ and $P_{\min 1} P_{\min 2}$ and oscillations observed in the results was not used in this component, as Figure 6 and 7.

After the closing of VDP in moments $t_{2 a}$ and $t_{2 b}$, we noticed again the damping effect generated by the accumulator. It was concluded that with the closing of the VDP, part of the pump was absorbed by the battery (energy storage process) rather than being quickly diverted by the VA and thereby avoided the sharp increase in supply pressure. Moreover, it was found that due to the dynamics of operation of the energy accumulation process performed by the accumulator occurred late in restoring the steady state in the set value $P_{A}$. As can be seen, the pulse pump accompanies every curve oscillation $P_{A}$.

\section{B. Analysis Fall $P_{S}$ depending on the operating conditions of the circuit}

According to the analysis on the dynamic behavior of $P_{S}$, it was found that the variation of the pressure, ie the pressure drop $P_{S}$ value is related to the decrease in the flow deflected by $Q_{D}$ VA. Decreased flow $Q_{D}$ depends on the increase of the flow $Q_{C}$ resulting from activation of the VDP, so this variation is related to the flow behavior through the VDP. Therefore, the analysis is based on the relationship of the operating conditions of the circuit, the VDP opening and loading of the cylinder, and falling $P_{S}$. Comparing the results, we also analyzed the effect of using the accumulator drop $P_{S}$.

\section{- Results $P_{S}$ drop without using the accumulator circuit}

For calculations of the fall of $P_{S}$ each test, we considered the difference between the pressure set on VA $P_{A}$ in continuous and steady state values that occurs during the opening of the VDP, as noted in the analysis of the dynamic behavior $P_{S}$. Each VDP open condition and charging the drum was repeated four times, after this we calculated the average pressure drop between these four values and the standard deviation of these results. The results are shown in Table I. 
PAPER

ANALYSIS BEHAVIOR IN A HydRAULIC SYSTEM IN THE SUPPLy PRESSURE VARIATION

TABLE I.

RESULTS IN THE PRESSURE AS FUNCTION OF LOADING AND OPENING OF THE VDP (WITHOUT ACCUMULATOR)

\begin{tabular}{|c|c|c|}
\hline & \multicolumn{2}{|c|}{ Loading - 20 kg } \\
\hline $\begin{array}{c}\text { Opening in the } \\
\text { VDP [\%] }\end{array}$ & $\begin{array}{c}\text { Falling } P_{S} \\
{[\%]}\end{array}$ & $\begin{array}{c}\text { Standard } \\
\text { Deviation (\%) }\end{array}$ \\
\hline 4 & 3,34 & 0,196 \\
\hline 6 & 3,78 & 0,147 \\
\hline 8 & 3,80 & 0,135 \\
\hline \multirow[t]{2}{*}{10} & 3,83 & 0,185 \\
\hline & \multicolumn{2}{|c|}{ Loading - 40 kg } \\
\hline $\begin{array}{c}\text { Opening in the } \\
\text { VDP [\%] }\end{array}$ & $\begin{array}{c}\text { Falling } P_{S} \\
{[\%]}\end{array}$ & $\begin{array}{c}\text { Standard } \\
\text { Deviation (\%) }\end{array}$ \\
\hline 4 & 3,09 & 0,102 \\
\hline 6 & 3,58 & 0,179 \\
\hline 8 & 3,61 & 0,229 \\
\hline \multirow[t]{2}{*}{10} & 3,63 & 0,204 \\
\hline & \multicolumn{2}{|c|}{ Loading - 60 kg } \\
\hline $\begin{array}{c}\text { Opening in the } \\
V D P[\%]\end{array}$ & $\begin{array}{c}\text { Falling } P_{S} \\
{[\%]}\end{array}$ & $\begin{array}{c}\text { Standard } \\
\text { Deviation (\%) }\end{array}$ \\
\hline 4 & 2,35 & 0,128 \\
\hline 6 & 2,74 & 0,145 \\
\hline 8 & 2,76 & 0,121 \\
\hline 10 & 2,79 & 0,192 \\
\hline
\end{tabular}

According to Figure 10, the relationship between the increasing opening of the VDP and $P_{S}$ variation for the three load conditions is approximately the same as can be observed in the linear behavior of each condition. This demonstrated that the relationship between the gap and increase the flow through the VDP was approximately the same in all three conditions of the cylinder, as this valve flow behavior observed in Figure 9.

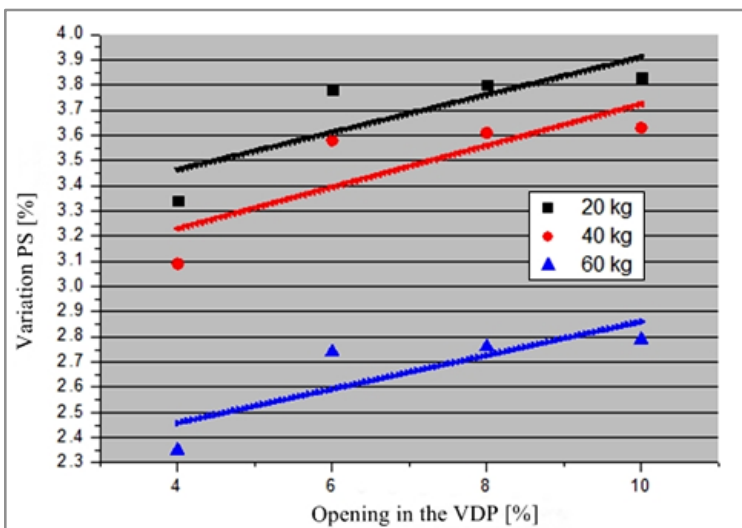

Figure 10. Variation of $P_{S}$ x aperture VDP (not using the accumulator in the circuit).

Relating to the graph described in Figure 4, the rise of the load pressure decreases the flow through the VDP. The increased load on the cylinder, that is, the load pressure, decreased flow through the VDP generating a smaller change in the flow diverted by VA, and consequently, the less variation in the supply pressure. The decrease in flow by VDP due to increased loading pressure was higher with the loading condition of $60 \mathrm{~kg}$ assuming drop $P_{S}$ relatively low compared to other loading conditions.

- Analysis of the drop $P_{S}$ using the accumulator in the circuit
The variation of $P_{S}$ using the battery in the circuit is calculated based on the values of $P_{A}$ steady state peak and minimum pressure (as Figure 11). Again, each of the VDP open condition and charging the drum was repeated four times, after that calculated the mean pressure drop from these four values and the standard deviation of these results. The results are shown in Table II.

TABLE II

RESUlTS IN THE PRESSURE AS FUNCTION OF LOADING AND OPENING OF THE VDP (WITH ACCUMULATOR)

\begin{tabular}{|c|c|c|}
\cline { 2 - 3 } \multicolumn{1}{c|}{} & \multicolumn{2}{c|}{ Loading - 20 kg } \\
\hline $\begin{array}{c}\text { Opening in the } \\
\text { VDP [\%] }\end{array}$ & $\begin{array}{c}\text { Falling } \boldsymbol{P}_{\boldsymbol{S}} \\
{[\%]}\end{array}$ & $\begin{array}{c}\text { Standard } \\
\text { Deviation (\%) }\end{array}$ \\
\hline 4 & 2,39 & 0,187 \\
\hline 6 & 2,79 & 0,191 \\
\hline 8 & 2,81 & 0,162 \\
\hline 10 & 2,84 & 0,148 \\
\hline & \multicolumn{2}{c|}{ Loading - 40 kg } \\
\hline $\begin{array}{c}\text { Opening in the } \\
\text { VDP [\%] }\end{array}$ & $\begin{array}{c}\text { Falling } \boldsymbol{P}_{\boldsymbol{S}} \\
{[\%]}\end{array}$ & $\begin{array}{c}\text { Standard } \\
\text { Deviation (\%) }\end{array}$ \\
\hline 4 & 2,33 & 0,114 \\
\hline 6 & 2,74 & 0,147 \\
\hline 8 & 2,75 & 0,149 \\
\hline 10 & 2,78 & 0,163 \\
\hline \multicolumn{2}{|c|}{ Loading - 60 kg } \\
\hline Opening in the & $\begin{array}{c}\text { Falling } \boldsymbol{P}_{\boldsymbol{S}} \\
{[\%]}\end{array}$ & $\begin{array}{c}\text { Standard } \\
\text { Deviation (\%) }\end{array}$ \\
\hline VDP [\%] & 2,09 & 0,113 \\
\hline 4 & 2,42 & 0,156 \\
\hline 6 & 2,43 & 0,132 \\
\hline 8 & 2,51 & 0,109 \\
\hline 10 & \multicolumn{2}{c|}{} \\
\hline
\end{tabular}

The use of accumulator caused a lower minimum peak pressure in the supply (Figure 8 and 9). Figure 11 shows the values were lower drop $P_{S}$ using the battery in the circuit. Comparing the linear behavior with the results without using the battery, it is noticed that in this case the relationship between openness and the fall of the VDP $P_{S}$ was higher.

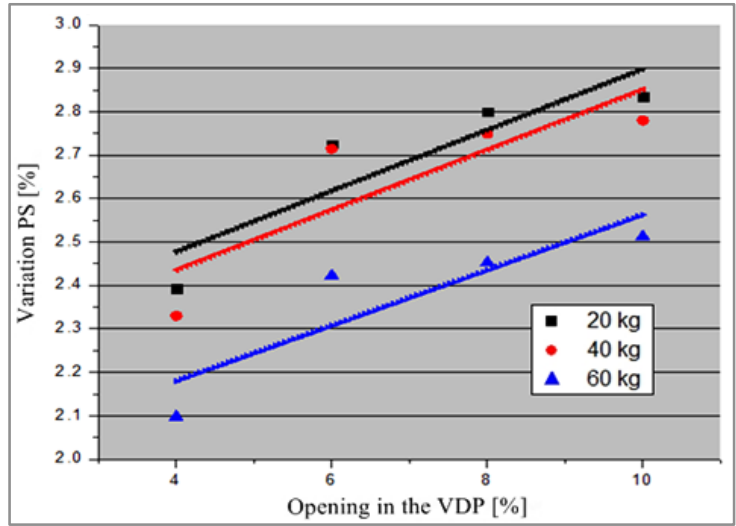

Figure 11. Variation of $P_{S} \times$ aperture VDP (using the accumulator in the circuit).

The Figure 12 shows that the reduction in drop $P_{S}$ taken by accumulator was higher in conditions with mass loading of 20 and $40 \mathrm{~kg}$. This fact means that the function of accumulator in the fall of compensation $P_{S}$ was more effective under conditions in which there was greater variation in pressure $P_{S}$, ie, the loadings of 20 and $40 \mathrm{~kg}$ in the cylinder, as seen in the results shown in Figure 10. 


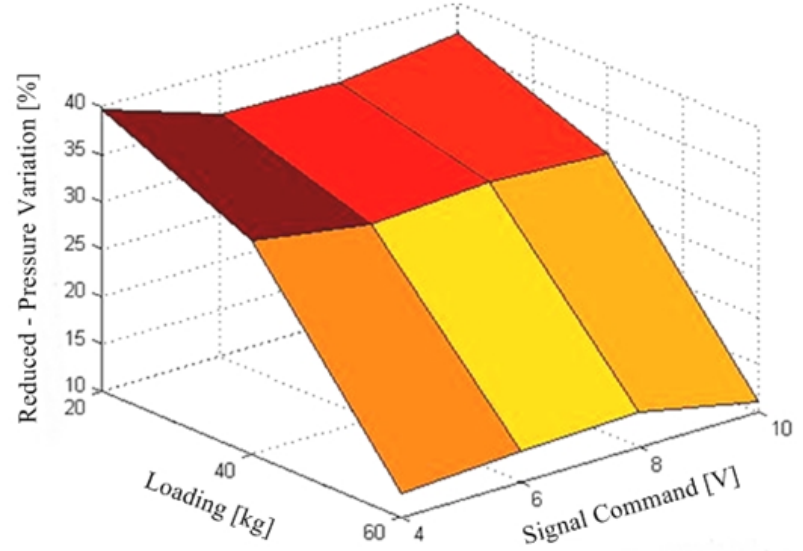

Figure 12. Reduction of variation $P_{S}$ from use of the accumulator

\section{FINAL CONSIDERATIONS}

With the development of this work can reach the following considerations:

- The behavior of the hydraulic power circuit, that is, flow and pressure depend directly on the operation of mechanical devices of the valves responsible for its control. Therefore, the operating characteristics of hydraulic components must be considered during the design of a hydraulic system;

- The delay in the response of the relief valve checked the result without the accumulator was greater with increasing flow variation through this. In a system that operates at high flows this phenomenon could be enlarged due shutter operation of the relief valve, which could bring damage to circuit components;

- The results showed that the accumulator pressure variations become smoother supply acting as a buffer and avoiding too much pressure peaks. It was also found that the variation reduction of supply made by the accumulator was greater in the most critical, ie, at times of high flow variation promoted by VDP cases;

- The results for the variation of pressure do not correspond to those found in real applications because it used components with low flow capacity;

- For future work is suggested to conduct similar experiments done in this work, however using control valves and power unit with capabilities similar to the values commonly used in industrial applications.

\section{REFERENCES}

[1] I. V. Linsingen. Fundamentos de Sistemas Hidráulicos. Florianópolis: Editora da UFSC, 2008. 386p.

[2] K. Dasgupta and R. Karmakar. Modelling and Dynamics of Single-Stage Pressure Relief Valve with Directional Damping. Simulation Modelling Practice and Theory - ELSEVIER, Vol. 10, pp. 51-67. 2002.

[3] C. Schwartz. Modeling and Analysis of a Stroke End Cushioning Device for Hydraulic Cylinders, (In Portuguese), M.Sc. Thesis, Universidade Federal de Santa Catarina, Florianopolis, S.C., Brazil, 2004. 110p.

[4] P. I. I. Pereira. Análise Teórico-Experimental de Controladores para Sistemas Hidráulicos. Dissertação de Mestrado, UFSC Universidade Federal de Santa Catarina, Florianópolis, 2006. $163 \mathrm{p}$.

[5] V. J. de Negri. Sistemas Hidráulicos e Pneumáticos para Automação e Controle - Parte III. Florianópolis: Universidade Federal de Santa Catarina, 2002 (apostila do curso de pósgraduação).

[6] H. L. Stewart. Hydraulic and Pneumatic for Production. New York: Industrial Press. 1977. 435p.

[7] Anthony. E. Fluid Power with Applications. 4 th ed. Ohio: Prentice Hall. 1997. 452p.

[8] R. Szpak. Análise Teórico-Experimental das Pressões em Posicionadores Hidráulicos. Dissertação de Mestrado, UFSC Universidade Federal de Santa Catarina, Florianópolis, 2008. $132 \mathrm{p}$.

[9] J. Watton. Fundamentals of Fluid Power Control. New York: Cambridge University Press. 2009. 489 p http://dx.doi.org/10.1017/CBO9781139175241

[10] M. G. Rabie. Fluid Power Engineering. $1^{\circ}$ ed. New York: Editora McGraw-Hill. 2009. 448p.

[11] S. Rao. Vibrações Mecânicas, São Paulo. Ed. Pearson Prentice Hall, 2008. 424p.

\section{AUTHORS}

R. M. Castro is teacher of Hydraulic Systems, of Department of Mechanical Engineering - Faculty SATC, Rua Pascoal Meller, 73, Criciúma-SC, Brazil (richard.castro@satc.edu.br).

Y. M. Morona is student of mechanical engineering, Faculty SATC, Rua Pascoal Meller, 73, Criciúma-SC, Brazil (yan_morona@hotmail.com)

K. Machado is student of mechanical engineering, Faculty SATC, Rua Pascoal Meller, 73, Criciúma-SC, Brazil (kaina.machado@hotmail.com)

L. C. C. Cavaler is teacher of Mechanical Manufacturing, of Department of Mechanical Engineering SATC, Rua Pascoal Meller, 73. Criciúma-SC, Brazil (luiz.cavaler@satc.edu.br)

A. S. Rocha is coordinator of the Laboratory of Mechanical Manufacturing - LDTM, Federal University of Santa Catarina - UFRGS, Porto Alegre-RS. (alexandre.rocha@ufrgs.br)

Submitted 12 August 2014. Published as resubmitted by the authors 25 October 2014. 